\title{
The Role of the Cysteine Fragments of the Nickel Binding Loop in the Activity of the Ni(II) Containing SOD Enzyme
}

Norbert Lihi ${ }^{a, b} *$, Dóra Kelemen ${ }^{a}$, Nóra $V$. May $^{c}$, István Fábián ${ }^{a, b}$

${ }^{a}$ Department of Inorganic and Analytical Chemistry, University of Debrecen, H-4032, Debrecen, Hungary

${ }^{b}$ MTA-DE Redox and Homogeneous Catalytic Reaction Mechanisms Research Group, University of Debrecen, H-4032, Debrecen, Hungary

${ }^{\mathrm{c}}$ Research Centre of Natural Sciences, H-1117, Budapest, Hungary 


\begin{abstract}
Detailed equilibrium, spectroscopic and SOD activity studies are reported on nickel(II) complexes formed with the $N$-terminally free HHDLPCGVY-NH ${ }_{2}$ (NiSODHH) and HCDLPHGVY-NH 2 (NiSODHC) peptides mimicking the nickel binding loop in NiSOD. In these model peptides, cysteine was incorporated in different positions in order to gain better insight into the role of the cysteine residues in NiSOD. The results are compared with those obtained with the wild-type fragment of NiSOD. The complex formation equilibria of nickel(II) with the two peptides exhibit different features. In the case of NiSODHH, the ligand field of the $\left(\mathrm{NH}_{2}, \mathrm{~N}_{\mathrm{Im}}, \mathrm{N}_{\mathrm{Im}}, \mathrm{S}^{-}\right)$donor set is not strong enough to cause spin pairing and an octahedral paramagnetic complex is formed under physiological conditions. In contrast, NiSODHC forms square-planar diamagnetic complex with $\left(\mathrm{NH}_{2}, \mathrm{~N}^{-}, \mathrm{S}^{-}, \mathrm{N}_{\mathrm{Im}}\right)$ donors which exhibits remarkable SOD activity. Our results unambiguously prove that the presence of cysteine in the secondary position of the peptide chain is crucial to establish the square-planar geometry in the reduced form of NiSOD, while the distant cysteine affects the redox properties of the $\mathrm{Ni}(\mathrm{II}) / \mathrm{Ni}$ (III) couple. Compared to the model systems, the Ni(II) complex with the wild-type fragment of NiSOD exhibits superior SOD activity. This confirms that both cysteinyl residues are essential in efficient degradation of superoxide ion. The enzyme mimetic complexes are also capable to assist the decomposition of superoxide ion, however, they show considerably smaller catalytic activity due to the absence of one of the cysteine residues.
\end{abstract}




\section{INTRODUCTION}

The superoxide dismutase enzymes (SODs) are a family of enzymes which keep the concentration of the reactive oxygen radicals at a controlled low limit by regulating the disproportionation of these radicals while harmless compounds are formed. ${ }^{1,2}$ Several metal ions in metalloenzymes play significant role in the degradation of the superoxide radical. ${ }^{3,4}$ One of them is the nickel containing SOD enzyme, ${ }^{5}$ where the nickel is in the active centre of the enzyme. The dismutation reaction occurs through a proton coupled electron transfer mechanism accompanied with the change of oxidation state of nickel between +2 and +3 . $^{6}$ NiSODs are homohexameric enzymes consisting four helix-bundle subunits and each unit contains a catalytically active metal ion. ${ }^{7}$ NiSODs feature an unique coordination environment where nickel(II) is accommodated by the terminal amino group, amide nitrogen and the two thiolate groups of cysteine residues. This coordination motif exhibits a loop within the first six amino acid residues (HisCysAspLeuProCys) from the N-terminal part of the enzyme. ${ }^{8}$ The oxidation of nickel(II) to nickel(III) leads to the binding of the terminal histidine in a squarepyramidal coordination environment, and the thiolate groups of cysteine remain intact indicating that the oxidation is metal-centered, not ligand based. Therefore, it was supposed that the cysteinates may alter the reactivity of the redox couple between $\mathrm{Ni}(\mathrm{II}) / \mathrm{Ni}(\mathrm{III}) .{ }^{9}{ }^{10} \mathrm{The}$ reduction potential of the wild-type NiSOD (290 mV vs. NHE) falls into the potential range of the oxidation and reduction of $\mathrm{O}_{2}{ }^{\bullet-} .{ }^{11}$ Earlier studies demonstrated, that the redox potential of $\mathrm{Ni}(\mathrm{II}) / \mathrm{Ni}(\mathrm{III})$ with $\mathrm{N} 2 \mathrm{O} 2$ donor set is considerably higher than with $\mathrm{N} 2 \mathrm{~S} 2$ coordination sphere. ${ }^{12}{ }^{13}$ Computational studies on the nickel - thiolate interactions confirmed that the redoxactive behaviour is due to the $\pi$-interaction between the $3 d$ orbital of nickel and $\pi$-based thiolate S orbital which destabilizes the molecular orbital. ${ }^{14}$

The crucial role of the peptide nitrogen in the coordination sphere was demonstrated through a synthesis of mutant NiSOD peptide where the amidated ligand was converted to secondary amine. The results indicated that this influence on nickel binding significantly decreases the 
rate of superoxide disproportionation. ${ }^{6}$ Most recently, Delangle and co-workers designed a sulfur-rich pseudopeptide ligand bearing nitrilotriacetic moiety. ${ }^{15}$ This low-molecular weight ligand possesses three cysteine moieties and nickel(II) is bound via the thiolate groups. At physiological $\mathrm{pH}$, the $\mathrm{S} 3 \mathrm{O}$ coordination set displays square-planar coordination environment with significant SOD activity, although the complex does not contain any nitrogen donor in the coordination sphere.

In our recent study, we examined the role of the terminal amino group of the NiSOD binding loop and explored the effect of the acetylation of the N-terminal amino group. The equilibrium studies clearly demonstrated that the $\mathrm{N}$-terminal amino group is the primary metal binding site for nickel(II). The acetylation of the peptide significantly reduces the nickel(II) binding affinity of the peptide, however, the oxidation resulted in the formation of nickel(III) coordination isomers which were confirmed by EPR spectroscopy. ${ }^{16}$ In contrast, the acetylation significantly enhances the zinc(II) binding ability of the peptide. ${ }^{17}$ The role of proline, which is the only vital non-coordinating residue within the Ni-binding loop, was also studied. ${ }^{18}$ The results confirmed that proline is able to alter the formation of the active site of the reduced form of NiSOD. However, there are no differences between the oxidized form of proline and alanine containing peptides. Both peptides possess the same square-pyramidal coordination environment with nickel(III) and both the g-values and hyperfine tensors are in good agreement with those obtained for the wild-type of NiSOD enzyme. ${ }^{7,16}$

The main objective of the present work is to demonstrate the role of the cysteine residues in the nickel binding loop. This paper reports detailed equilibrium, spectroscopic and SOD activity studies on metallopeptides containing cysteine in alternative positions. These are the HisHisAspLeuProCysGlyValTyr-NH $\mathrm{NH}_{2}$ (NiSODHH, HHDLPCGVY-NH2) and HisCysAspLeuProHisGlyValTyr-NH2 $\left(\right.$ NiSODHC, HCDLPHGVY-NH ${ }_{2}$ ) peptides and the results are compared with those observed for the wild-type fragment 
(HisCysAspLeuProCysGlyValTyr-NH2, wtNiSOD, HCDLPCGVY-NH 2 ) (Scheme 1). The stability constants of the nickel(II) complexes formed in aqueous solution were determined by $\mathrm{pH}$-potentiometric titrations and the coordination modes of the corresponding complexes were characterized by UV-Vis, CD and MS methods. The feasibility of the oxidation of the nickel(II) complexes was investigated in the reaction with $\mathrm{KO}_{2}$ and Oxone, and the formation of the transient species was followed by EPR spectroscopy. The SOD activity of the complexes was studied by utilizing the xanthine/xanthine oxidase/NBT system.<smiles>CC(C)CC(NC(=O)C(CC(=O)O)NC(=O)CCS)C(=O)N1CCCC1C(=O)NCC(=O)NCC(=O)NC(C)C(=O)NC(Cc1ccc(O)cc1)C(N)=O</smiles>

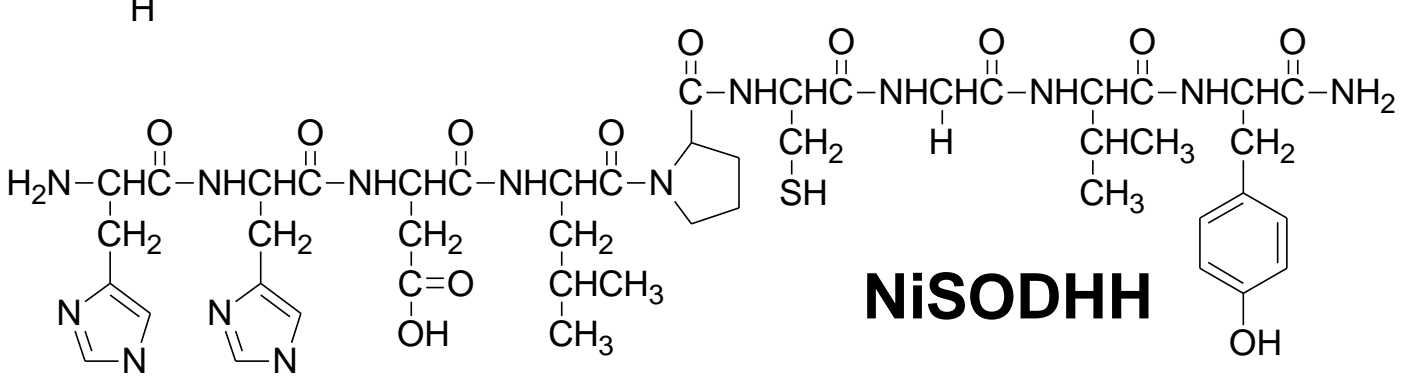
$\mathrm{H}$

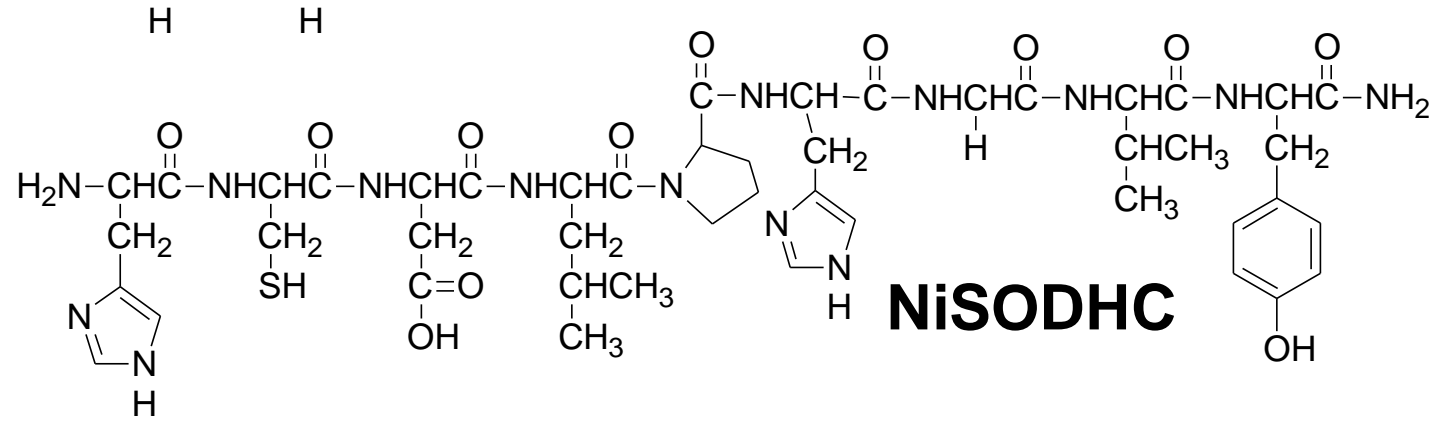

Scheme 1. Structural Formulas of the Ligands Examined in this Study. 


\section{EXPERIMENTAL}

\section{Materials}

The peptides used in this study were purchased from Synpeptide Co. (Shanghai, China) and used without further purification. The concentration of the peptide stock solutions was determined by $\mathrm{pH}$-potentiometric titrations. $\mathrm{The} \mathrm{NiCl}_{2}$ stock solution was prepared from the highest available grade ( $\geq 99.95 \%$ (VWR Int., USA)) and its concentration was checked gravimetrically via the precipitation of oxinate. Xanthine $(0.5 \mathrm{U} / \mathrm{mg})$, xanthine oxidase, nitro blue tetrazolium chloride (NBT) and $\mathrm{KO}_{2}$ were purchased from Sigma-Aldrich. For solution equilibrium and spectroscopic studies, triple deionized and ultrafiltered (Millipore Q system) water was used.

pH-potentiometry

The protonation constants $\left(\log K_{\mathrm{i}}\right)$ of the ligands and the overall stability constants $\left(\log \beta_{\text {pqr }}\right)$ were determined by $\mathrm{pH}$-potentiometric titration method using carbonate ion free $\mathrm{KOH}$ solution. The carbonate contamination (less than $0.05 \%$ ) was determined using the appropriate Gran functions. ${ }^{19}$ In these titrations, 3 or $4 \mathrm{~mL}$ aliquots of the ligands (ca. $1.2 \mathrm{mM}$ ) were titrated and the metal to ligand ratio was between $1: 1$ and $1: 2(I=0.2 \mathrm{M}$ using $\mathrm{KCl}, T=298 \mathrm{~K})$. Oxygen and carbon dioxide were eliminated by purging the samples prior and the headspace over the sample during the titrations with argon. The samples were stirred using a VELP scientific magnetic stirrer and the $\mathrm{pH}$ measurements were made using a MOLSPIN $\mathrm{pH}$-meter equipped with a 6.0234.110 combined glass electrode (Metrohm) and a MOL-ACS microburette. The $\mathrm{pH}$ readings were converted to hydrogen ion concentrations as described by Irving et al. ${ }^{20}$ Protonation constants and the overall stability constants, $\beta_{\mathrm{pqr}}=\left[\mathrm{Ni}_{\mathrm{p}} \mathrm{L}_{\mathrm{q}} \mathrm{H}_{\mathrm{r}}\right] /[\mathrm{Ni}]^{p}[\mathrm{~L}]^{q}[\mathrm{H}]^{r}$ of the nickel(II) complexes (charges are omitted for the sake of simplicity) were calculated by using the designated computational programs, SUPERQUAD ${ }^{21}$ and PSEQUAD ${ }^{22}$. Efficient removal of oxygen from the samples and the reversibility of the titration were tested as follows. First, a 
solution of peptide was titrated with $\mathrm{KOH}$. In the end of the titration, the alkaline sample was acidified and subsequently re-titrated. A good agreement between the first and second titration curves and the calculated ligand concentration indicated that the ligand was not oxidized even under alkaline conditions.

\section{Spectroscopic measurements}

UV-visible spectra of the nickel(II) complexes were recorded with an Agilent Technologies Cary 8454 UV-VIS diode array spectrophotometer in the 200 - $800 \mathrm{~nm}$ wavelength range using the same concentration range as in the $\mathrm{pH}$-potentiometric titrations. The individual spectra of the complexes were calculated by solving the overdetermined linear equation system with MATLAB. $^{23}$ The circular dichroism spectra were registered with a Jasco J-810 spectropolarimeter using $1 \mathrm{~mm}$ and/or $1 \mathrm{~cm}$ cells in the $250-800 \mathrm{~nm}$ wavelength range. All CW-EPR spectra were recorded with a BRUKER EleXsys E500 spectrometer (microwave frequency $9.45 \mathrm{GHz}$, microwave power $13 \mathrm{~mW}$, modulation amplitude $5 \mathrm{G}$, modulation frequency $100 \mathrm{kHz}$ ). An $0.2 \mathrm{~mL}$ aliquot of $\mathrm{Ni}(\mathrm{II})$ sample solution was introduced into a quartz EPR tube, then $0.1 \mathrm{~mL}$ DMSO solution containing $\mathrm{KO}_{2}$ (Acros Organics) or Oxone was added for in situ oxidation. Frozen solution EPR spectra were measured in a Dewar container filled with liquid nitrogen at $77 \mathrm{~K}$. The measured spectra were corrected by the baseline spectrum measured in the same way, and simulated using a designated EPR program. ${ }^{24}$

$400 \mathrm{MHz}{ }^{1} \mathrm{H}$ NMR spectra were recorded on a Bruker Avance I 400 spectrometer at $298 \mathrm{~K}$. The chemical shifts were referenced to sodium 3-(trimethylsilyl)-1-propane sulfonate (TSP, $\delta_{\text {TSP }}=0.00 \mathrm{ppm}$ ) dissolved in the sample and $\mathrm{D}_{2} \mathrm{O}$ was used as a solvent.

${ }^{17} \mathrm{O}$ NMR measurements were carried out with a Bruker Avance DRX $360 \mathrm{MHz}$ spectrometer at $298 \mathrm{~K}$. The T2 relaxation times were acquired by using the Carr-Purcell-Meiboom-Gill sequence (CPMG).

Mass spectrometry 
ESI-TOF-MS measurements were made with a Bruker maXis II MicroTOF-Q type Qq-TOFMS instrument (Bruker Daltonik, Bremen, Germany) in negative mode. The instrument was equipped with an electrospray ion source where the spray voltage was $4 \mathrm{kV} \cdot \mathrm{N}_{2}$ was utilized as a drying gas and the drying temperature was $200{ }^{\circ} \mathrm{C}$. The spectra were accumulated and recorded using a digitalizer at a sampling rate of $2 \mathrm{GHz}$. The mass spectra were calibrated externally using the exact masses of sodium formiate clusters. The spectra were evaluated using DataAnalysis 4.4 software from Bruker. The isotopic patterns of the complexes were calculated using the IsotopePattern software from Bruker.

In the MS and spectrophotometric measurements, the samples were freshly prepared and purged with argon, and the $\mathrm{pH}$ was adjusted immediately before the samples were introduced into the ESI-source or transferred into the cuvettes.

\section{SOD activity measurements}

In these experiments, the xanthine/xanthine oxidase system was used to generate the superoxide anion radical $\left(\mathrm{O}_{2}{ }^{\bullet-}\right)$ which reacts with para-nitro blue tetrazonium chloride (NBT) to produce diformazan with characteristic molar absorptivity at $560 \mathrm{~nm}$. The process can readily be followed by UV-VIS spectroscopy. The addition of the putative SOD mimic to this system prevents the reduction of NBT. The assay was carried out in phosphate buffer $(0.05 \mathrm{M})$ containing NBT $\left(4.5 \times 10^{-5} \mathrm{M}\right)$ and xanthine $\left(2 \times 10^{-4} \mathrm{M}\right)$. The reaction was initiated by adding an appropriate amount of xanthine oxidase to produce around $0.020-0.028 \mathrm{~min}^{-1}$ rate of the absorbance change at $560 \mathrm{~nm}$. First, the reaction was monitored in a blank sample (without adding any nickel(II) complex) for 3-4 min. Then the nickel(II) complex was added to the same sample and the absorbance was monitored for another $4 \mathrm{~min}$. The corresponding rates were obtained by fitting the experimental data to a straight line. The SOD-activity was expressed as the $\mathrm{IC}_{50}$ value which was converted into rate constants as described elsewhere in detail. ${ }^{25,26}$ Stopped-flow measurements 
The catalytic activities of the $\mathrm{Ni}(\mathrm{II})$ complexes in the decomposition of $\mathrm{O}_{2}{ }^{-}$were tested in fast kinetic experiments using an Applied Photophysics SX-20 stopped-flow instrument equipped with a photomultiplier tube as the detector. The kinetic traces were collected using $2 \mathrm{~mm}$ optical path length and the experiments were performed at $22{ }^{\circ} \mathrm{C}$. In order to avoid the relatively fast decomposition of $\mathrm{KO}_{2}$ in aqueous solution, this reagent was prepared in DMSO. According to our preliminary experiments, mixing water and DMSO in a single-mixing experiment produced an absorbance change lasting for about $1 \mathrm{~min}$. This fake kinetic effect most likely corresponds to light scattering in the observation cell due to the relatively slow homogenization of the solvent mixture. This problem was circumvented by using the instrument in sequential mode which is useful for triggering a reaction without altering the solvents of the reagents. The first syringe was filled with aqueous HEPES buffer $(20 \mathrm{mM}, \mathrm{pH} 7.8)$, the second one with $\mathrm{KO}_{2}$ in DMSO while the third one with the complex dissolved in 1:1 DMSO and aqueous HEPES buffer. In the first phase of these experiments, the aging loop was filled with the 1:1 mixture of the first and second solutions to produce a $\mathrm{KO}_{2}$ reagent in 1:1 water-DMSO solvent. After 80 s incubation time, this mixture was reacted with the solution in the third syringe and the progress of the reaction was monitored at $250 \mathrm{~nm}$.

The $\mathrm{O}_{2}^{-}$solutions were freshly prepared before each experiment by dissolving solid $\mathrm{KO}_{2}($ Acros Organics) in vigorously stirred DMSO.

\section{RESULTS AND DISCUSSION}

\section{Acid-base equilibria of the peptides}

The acid dissociation constants of the peptides $\left(\log K_{\mathrm{i}}\right)$ were determined by $\mathrm{pH}$-potentiometry and are collected in Table 1. 
Table 1. The stepwise deprotonation constants $\left(\log K_{\mathrm{i}}\right)$ of the peptides. ${ }^{\dagger} I=0.2 \mathrm{M} \mathrm{KCl}, T=298$

$\mathrm{K}$

\begin{tabular}{|c|c|c|c|}
\hline & NiSODHC & NiSODHH & wtNiSOD $^{\mathrm{a}}$ \\
\hline \multicolumn{4}{|l|}{ Species } \\
\hline$\left[\mathrm{H}_{6} \mathrm{~L}\right]^{3+/ 2+}$ & $3.41(6)$ & $3.37(6)$ & 3.58 \\
\hline$\left[\mathrm{H}_{5} \mathrm{~L}\right]^{2+/+}$ & $5.44(5)$ & $5.35(6)$ & 5.48 \\
\hline$\left[\mathrm{H}_{4} \mathrm{~L}\right]^{+/ 0}$ & $6.51(4)$ & $6.44(4)$ & 7.20 \\
\hline$\left[\mathrm{H}_{3} \mathrm{~L}\right]^{0 /-}$ & $7.33(4)$ & $7.33(3)$ & 8.25 \\
\hline$\left[\mathrm{H}_{2} \mathrm{~L}\right]^{-/ 2-}$ & $8.66(3)$ & $8.57(2)$ & 8.92 \\
\hline$[\mathrm{HL}]^{2-/ 3-}$ & $9.89(2)$ & $9.85(2)$ & 9.88 \\
\hline$\Sigma \log K_{\mathrm{i}}$ & 41.24 & 40.91 & 43.31 \\
\hline
\end{tabular}

$\dagger 3 \sigma$ standard deviations are indicated in parentheses.

${ }^{\text {a }}$ Data are taken from Ref. ${ }^{16}$

In accordance with the structures of the peptides, the terminal amino group, the side chain of aspartic acid, the thiol group of cysteine, the hydroxyl group of tyrosine as well as the two imidazole rings of histidine residues are taking part in the acid-base processes. On the basis of plausible considerations, the $\operatorname{lowest} \log K_{\mathrm{i}}$ value is assigned to the carboxylic group of aspartic acid, while the highest $\log K_{\mathrm{i}}$ belongs to the tyrosine moiety. The second deprotonation step occurs on the imidazole ring at the N-terminus which has increased acidity compared to free imidazole. Such a feature has already been reported for several N-terminally free peptides and explained by considering that the formation of an intramolecular $\mathrm{H}-$ bond between the Nterminal amino group and imidazole-N leads to the increased acidity. ${ }^{27} 28$ The same scenario is expected in the systems examined in this work. Further deprotonation processes significantly overlap, however, it is important to note that the basicity of the model peptides is lower than that of wtNiSOD which is due to the replacement of a cysteine moiety with histidine. Thus, the nickel(II) complexes of the model peptides are expected to be less stable compared to those formed with wtNiSOD.

Both model peptides exhibit very similar acid-base properties, i.e. the alternation of internal position of the histidine residues does not have significant effect on these features. 


\section{Nickel(II) complexes of the peptides}

The overall stability constants of the nickel(II) - peptide complexes $\left(\log \beta_{\mathrm{pqr}}\right)$ obtained by $\mathrm{pH}$ potentiometric method are listed in Table 2 and the corresponding titration curves are reported in the Supporting Information (Figure S1 and S2). The formation of precipitates was not observed during the titrations which was also confirmed by the pH-dependent UV-Vis experiments. The complex formation processes of the two model peptides differ significantly, therefore, the equilibrium features of the two systems are discussed separately in the subsequent part of the paper.

Table 2. The stability constants $\left(\log \beta_{\mathrm{pqr}}\right)$ of the complexes formed between Nickel(II) and the peptides. ${ }^{\dagger} I=0.2 \mathrm{M} \mathrm{KCl}, T=298 \mathrm{~K}$

\begin{tabular}{|c|c|c|c|}
\hline & NiSODHC & NiSODHH & wtNiSOD $^{\mathrm{a}}$ \\
\hline \multicolumn{4}{|l|}{ Species } \\
\hline$\left[\mathrm{NiH}_{3} \mathrm{~L}\right]^{2+/+}$ & $31.60(2)$ & $31.38(3)$ & 33.44 \\
\hline$\left[\mathrm{NiH}_{2} \mathrm{~L}\right]^{+}$ & & $25.69(7)$ & \\
\hline$[\mathrm{NiHL}]^{0 /-}$ & $20.57(2)$ & $20.44(3)$ & 22.22 \\
\hline$[\mathrm{NiL}]^{-1 / 2-}$ & $14.23(3)$ & $11.95(5)$ & 15.71 \\
\hline$\left[\mathrm{NiH}_{-1} \mathrm{~L}\right]^{2-/ 3-}$ & $4.62(5)$ & $2.16(5)$ & 6.45 \\
\hline $\log K\left(\mathrm{~N}^{-}\right)^{\mathrm{b}}$ & 5.52 & 8.49 & 6.51 \\
\hline Fitted pH-range & $3.2-11.2$ & $3.4-11.2$ & \\
\hline \multicolumn{4}{|c|}{${ }^{\dagger} 3 \sigma$ standard deviations are indicated in parentheses. } \\
\hline \multicolumn{4}{|c|}{${ }^{a}$ Data are taken from Ref. ${ }^{16}$} \\
\hline \multicolumn{4}{|c|}{${ }^{\mathrm{b}}$ Equilibrium constant for the deprotonation of amide $\mathrm{N}$. } \\
\hline $\log K\left(\mathrm{~N}^{-}\right)=\log \beta$ & $\mathrm{L})-\log \beta(\mathrm{NiL}$ & & \\
\hline
\end{tabular}

The complex formation reactions of NiSODHH starts in the slightly acidic $\mathrm{pH}$-range with the $\left[\mathrm{NiH}_{3} \mathrm{~L}\right]^{2+}$ complex (Figure 1).

It is well-known that the $\mathrm{N}$-terminally free peptides containing histidine in the first position easily form histamine-like coordinated complexes. ${ }^{29}{ }^{30}$ The presence of the same structural arrangement in NiSODHH suggests such a coordination mode with paramagnetic character. The corresponding equilibrium constant is calculated using equation 1 where $\mathrm{p} K_{\mathrm{a}}(\mathrm{OH})$, 
$\mathrm{p} K_{\mathrm{a}}(\mathrm{SH})$ and $\mathrm{p} K_{\mathrm{a}}(\mathrm{Im})$ are assigned to the hydroxyl function of tyrosine, the thiol group of cysteine and imidazole moiety of the distant histidine, respectively:

$$
\log K_{\text {Histamine-like }}(\mathbf{N i S O D H H})=\log \beta\left(\mathrm{NiH}_{3} \mathrm{~L}\right)-\mathrm{p} K_{\mathrm{a}}(\mathrm{OH})-\mathrm{p} K_{\mathrm{a}}(\mathrm{SH})-\mathrm{p} K_{\mathrm{a}}(\operatorname{Im})=5.63 .
$$

This value is very close to the $\log K$ of the $\mathrm{NiHL}$ complex of $\mathrm{HCA}-\mathrm{NH}_{2}\left(\log K_{\text {Histamine-like }}(\mathrm{HCA}\right.$ $\left.\left.\mathrm{NH}_{2}\right)=6.44\right)$ and consistent with the aforementioned assumption regarding the coordination mode. ${ }^{16}$ It is important to note, that the carboxylate group of the aspartic acid residue is already deprotonated in this pH-range where the $\left[\mathrm{NiH}_{3} \mathrm{~L}\right]^{2+}$ is the major species, however, its contribution to the metal binding is unlikely.

Upon increasing the $\mathrm{pH}$, further base consumption process leads to the formation of $\left[\mathrm{NiH}_{2} \mathrm{~L}\right]^{+}$ species, however, this complex is only a minor species and its formation overlaps with the formation of [NiHL] (Figure 1). Neither UV-VIS nor CD spectra show characteristic changes in this $\mathrm{pH}$ range, thus, the [NiHL] complex is expected to be octahedral exhibiting paramagnetic behaviour (Figure S3 and S4).

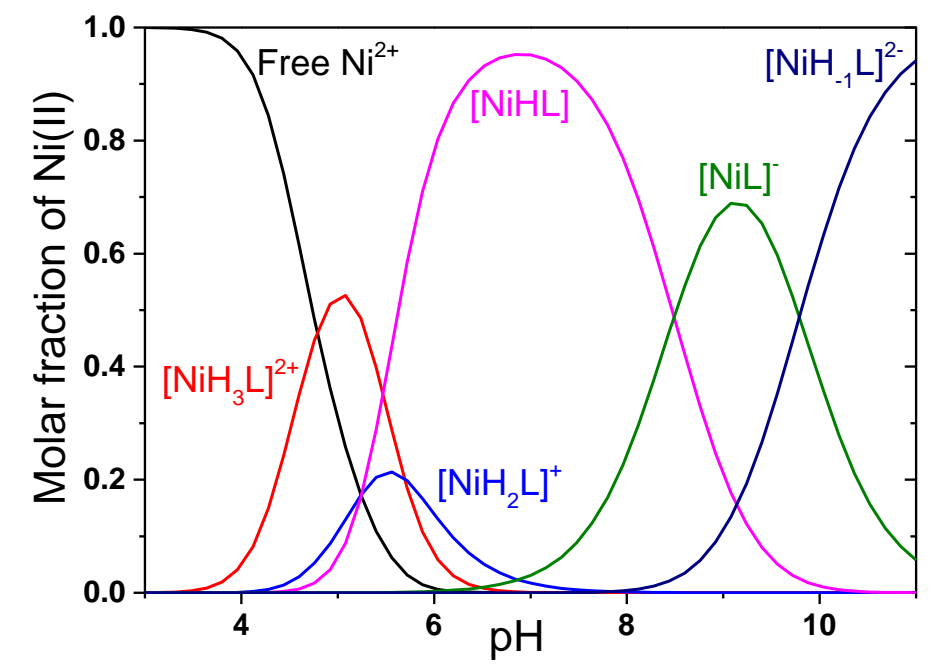

Figure 1. Distribution of the complexes formed in the $\mathrm{Ni}(\mathrm{II}) / \mathrm{NiSODHH} 1: 1$ system as a function of $\mathrm{pH}(I=0.2 \mathrm{M} \mathrm{KCl}, T$ $=298 \mathrm{~K}) \cdot c_{\mathrm{M}}=1.4 \mathrm{mM}$ 
The charge transfer band at $320 \mathrm{~nm}$ provides evidence for the binding of the thiolate group in NiHL (Figure S3). On the basis of this observation, it is reasonable to assume that four donor atoms are involved in binding to the metal ion. Considering the basicity of the individual donor groups in the ligand, it is envisioned that the terminal amino group, the thiolate group of cysteine as well as the two imidazoles of histidines are coordinated. To confirm this binding mode, ${ }^{1} \mathrm{H}$ NMR experiments were carried out. The ${ }^{1} \mathrm{H}$ NMR spectra were recorded in the absence and presence of 0.1 equivalent of nickel(II) and are presented in Figure S5. The formation of paramagnetic species is confirmed by the significant line broadening of the peaks, nevertheless, the ${ }^{1} \mathrm{H}$ NMR spectra offer a possibility to assign the donors coordinated to the metal ion. The aromatic region of the ${ }^{1} \mathrm{H}$ NMR spectrum dramatically changes after the addition of 0.1 equivalent of nickel(II) confirming that the imidazole nitrogens are coordinated, while the aromatic protons of the tyrosine moiety remain intact corroborating that the tyrosine $\mathrm{O}^{-}$ does not participate in binding the metal ion. The paramagnetism of the complex is corroborated by NMR experiments. At $\mathrm{pH} \sim 7.1, \mathrm{Ni}(\mathrm{II})$ almost exclusively exists as the [NiHL] complex. Thus, the significant ${ }^{1} \mathrm{H}$ line-broadening and the substantial decrease of the measured ${ }^{17} \mathrm{O}$ spinspin relaxation time of the bulk water in NiSODHH solution confirms that [NiHL] is paramagnetic and, as such, octahedral (Table 3).

Table 3. ${ }^{1} \mathrm{H}$ linewidth and ${ }^{17} \mathrm{O}$ spin - spin relaxation time $\left(T_{2}\right)$ of the bulk water in pure water and aqueous solutions of $\mathrm{NiCl}_{2}$ and $\mathbf{N i S O D H H}$ at $\mathrm{pH} 7.1$

\begin{tabular}{ccc}
\hline & ${ }^{1} \mathrm{H}$ linewidth & ${ }^{17} \mathrm{O} \mathrm{T} 2$ relaxation \\
\cline { 2 - 2 } $\mathrm{H}_{2} \mathrm{O}$ & $5.7 \mathrm{~Hz}$ & $6.58 \mathrm{~ms}$ \\
$\mathrm{NiCl}_{2}{ }^{\text {a }}$ & $35 \mathrm{~Hz}$ & $2.92 \mathrm{~ms}$ \\
NiSODHH & & \\
& $57 \mathrm{~Hz}$ & \\
\hline${ }^{\mathrm{a}} c_{\mathrm{Ni}(\mathrm{II})}=50 \mathrm{mM}$ & & \\
${ }^{\mathrm{b}} c_{\mathrm{Ni}(\mathrm{II})}=6.3 \mathrm{mM}$ & &
\end{tabular}


A further base consumption process results in the formation of the $[\mathrm{NiL}]^{-}$complex which is accompanied with drastic changes both in the UV-VIS and CD spectra (Figure S3 and S4). The calculated individual spectra of the complexes are reported in the Supporting Information. (Figure S6).

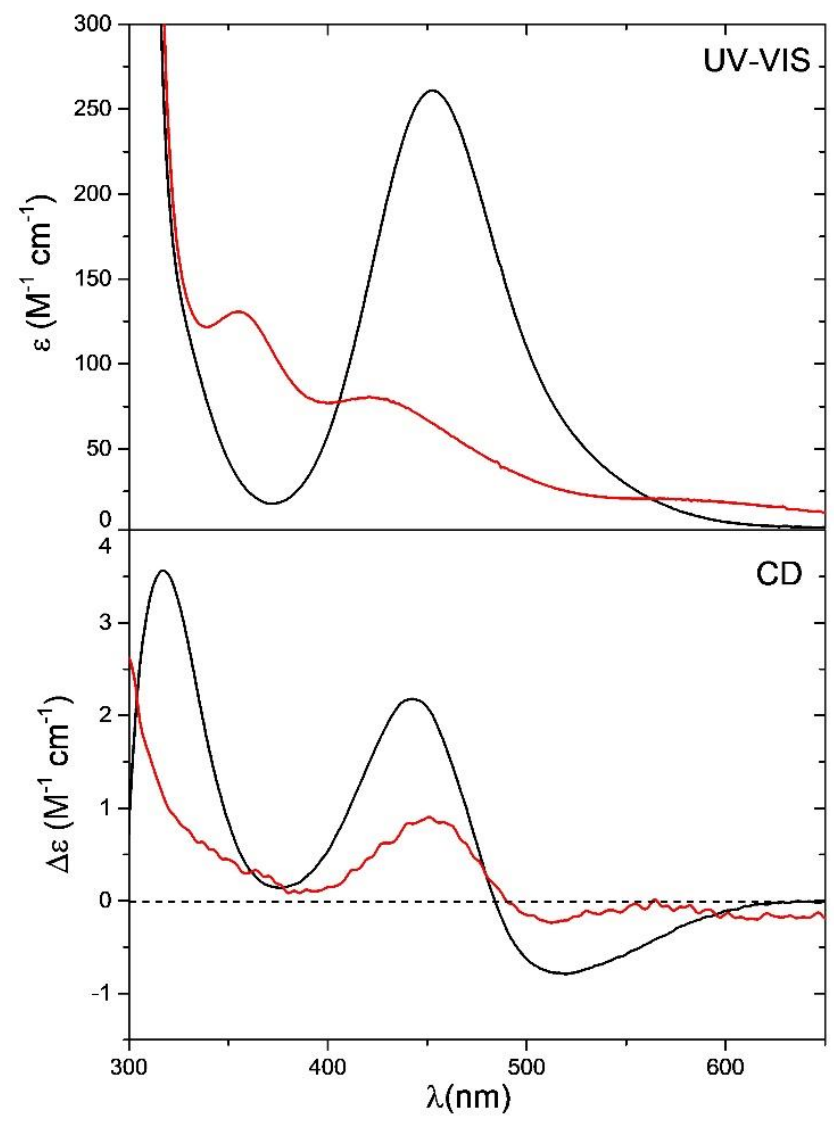

Figure 2. UV-VIS and CD spectra of the NiL complexes with NiSODHH (red) and NiSODHC (black).

An intensive band was observed at $430 \mathrm{~nm}$ which is a characteristic $d$ - $d$ band for diamagnetic square-planar nickel(II) complexes (Figure 2). The $[\mathrm{NiL}]^{-}$complex features the $\left(\mathrm{NH}_{2}, \mathrm{~N}^{-}, \mathrm{N}_{\mathrm{Im}}\right)$ chelate system which is supported by macrochelation due to the distant cysteinyl residue. The positive Cotton effect at $450 \mathrm{~nm}$ indicates that the first amide nitrogen is involved in the metal ion coordination, while a small intensity $\mathrm{CD}$ activity at around $500 \mathrm{~nm}$ confirms the existence of the thiolate group in the coordination sphere. The same conclusion has been reached earlier 
for the nickel(II) complex of AHAAAC-NH 2 peptide. ${ }^{31}$ Consequently, the imidazole-N of the first histidine is replaced by amide nitrogen of the peptide backbone in the $[\mathrm{NiL}]^{-}$complex. The stability constant of the $[\mathrm{NiL}]^{-}$complex of NiSODHH is four orders of magnitude smaller than the corresponding complex formed with wtNiSOD. This effect can easily be explained by the lack of the cysteine residue in the former ligand. Moreover, the calculated equilibrium constants for the amide nitrogen coordinated species is two orders of magnitude higher than that observed for wtNiSOD (Table 2.). Thus, the lack of cysteine in the secondary position shifts the deprotonation and coordination of peptide nitrogen to the alkaline $\mathrm{pH}$ range.

In alkaline solution, the deprotonation of the non-coordinating tyrosine moiety yields the $\left[\mathrm{NiH}_{-}\right.$ $\left.{ }_{1} \mathrm{~L}\right]^{2-}$ complex. The corresponding deprotonation constant, $\log K=9.79$, is close to that of the $\log K_{\mathrm{i}}$ of the side chain of tyrosine $\mathrm{OH}$ group in the free ligand $\left(\log K_{\mathrm{i}}=9.85\right)$ indicating that the coordination sphere of nickel(II) remains intact. Indeed, the UV-VIS and the CD spectra did not show any reorganisation in the coordination sphere confirming that the tyrosine $\mathrm{O}^{-}$does not have any contribution to the binding of the metal ion. The results of the ESI-TOF-MS measurements are consistent with the postulated species (Figure S7). In negative mode, the detected main ion is the $\mathrm{H}\left[\mathrm{NiH}_{-1} \mathrm{~L}\right]^{-}$complex (L refers to NiSODHH) and the experimental and calculated $\mathrm{m} / \mathrm{z}$ values as well as the isotope pattern are in good agreement confirming the existence of this complex.

Nickel(II) complexes of NiSODHC significantly differ from those of NiSODHH which can easily be explained by the different positions of the cysteine residue in the peptide chain. The complex formation starts in the slightly acidic pH-range with $\left[\mathrm{NiH}_{3} \mathrm{~L}\right]^{2+}$ and the $\left(\mathrm{NH}_{2}, \mathrm{~N}_{\mathrm{Im}}\right)$ donors are coordinated to the metal centre. The stability constant of $\left[\mathrm{NiH}_{3} \mathrm{~L}\right]^{2+}$ is similar to that of NiSODHH confirming the histamine-like coordination mode $\left(\log K_{\text {Histamine-like( NiSODHC })}\right.$ = 5.72). Upon increasing the $\mathrm{pH}$, the next processes lead to the binding of both the amide nitrogen and thiolate group of cysteine in a cooperative manner and the square-planar 
coordination sphere of nickel(II) is occupied by the $\left(\mathrm{NH}_{2}, \mathrm{~N}^{-}, \mathrm{S}^{-}\right)$donor set. A characteristic band at $450 \mathrm{~nm}$ in the UV-VIS spectra emerges simultaneously with the formation of [NiHL] ${ }^{+}$ complex confirming the equilibrium model (Figure 3).

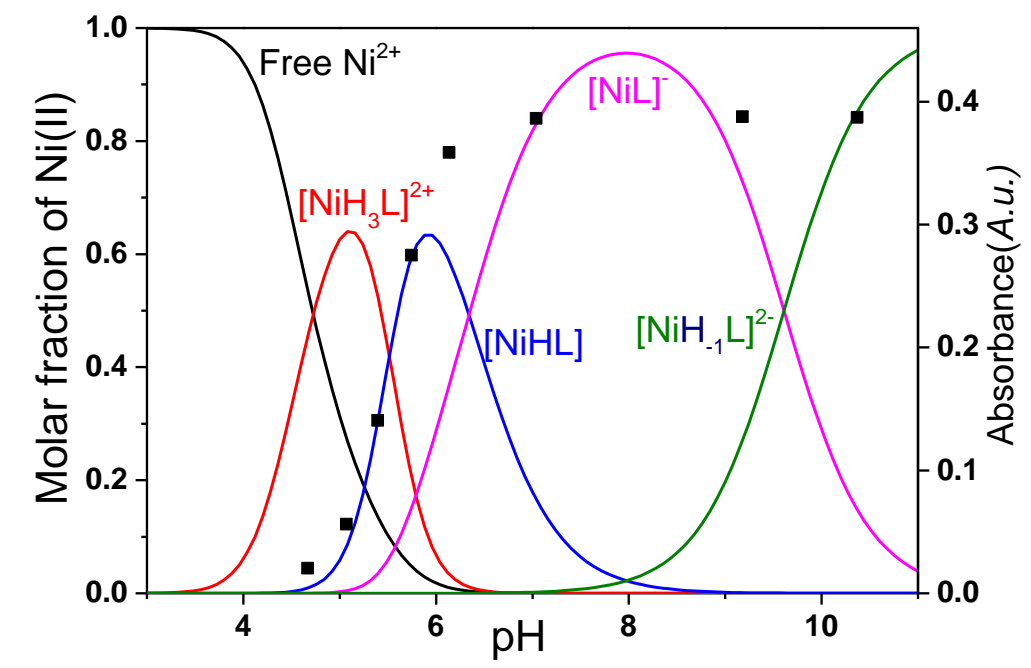

Figure 3. The concentration distribution of the complexes formed in the $\mathrm{Ni}(\mathrm{II}) / \mathrm{NiSODHC}$ system (lines) and the absorbance at $450 \mathrm{~nm}$ (匹) as a function of $\mathrm{pH}$ at 1:1 metal to ligand ratio $(I=0.2 \mathrm{M} \mathrm{KCl}, T$ $=298 \mathrm{~K}) \cdot c_{\mathrm{M}}=1.4 \mathrm{mM}$

In this complex, the binding of the first imidazole-N may be unfeasible because of steric effect due to the almost perfect plane formed by the $\left(\mathrm{NH}_{2}, \mathrm{~N}^{-}, \mathrm{S}^{-}\right)$donors in a square-planar crystal field. A further base consumption process leads to the formation of $[\mathrm{NiL}]^{-}$. In this complex, the $\left(\mathrm{NH}_{2}, \mathrm{~N}^{-}, \mathrm{S}^{-}\right)$coordination environment of nickel(II) is completed by the binding of the distant imidazole moiety of histidine. The equilibrium constant of the formation of $[\mathrm{NiL}]^{-}$complex is 6.34, which value is close to the $\mathrm{p} K_{\mathrm{a}}$ of the distant histidyl residue $\left(\mathrm{p} K_{\mathrm{a}}=6.51\right)$. The small difference between the equilibrium constants indicates a weak interaction between the metal ion and the imidazole-N of histidine. However, the CD spectra clearly show the binding of the distant imidazole. At $270 \mathrm{~nm}$, where the $\mathrm{Ni}(\mathrm{II})-\mathrm{Im}$ as well as the $\mathrm{Ni}(\mathrm{II})-\mathrm{N}_{\text {amide }}$ charge transfer bands are characteristic, the intensity increases parallel with the formation of $[\mathrm{NiL}]^{-}$species and reaches its maximum at $\mathrm{pH} 8$. In this $\mathrm{pH}$ range, the $[\mathrm{NiL}]^{-}$complex is the dominant species. 
(Figure S8). It should be noted that the formation of an $[\mathrm{NiL}]^{-}$isomer with non-coordinating imidazole can also be envisioned. In this case, the fourth equatorial position would be occupied by a water molecule. In alkaline solution, the deprotonation of the coordinated water molecule would lead to the formation of mixed hydroxido species, but such processes were not observed in our system. Accordingly, the formation of the noted isomer is unlikely but cannot be excluded.

UV-VIS and CD spectroscopic studies also confirm that the complex has square-planar geometry (Figure S9 and S10). The [NiL] $]^{-}$complex with a stoichiometry of $\left[\mathrm{NiH}_{-1} \mathrm{~L}\right](\mathrm{H})$, where the tyrosine residue on the C-termini remains protonated, is dominant under physiological conditions. On the basis of these results, the square-planar geometry is stabilized by strong field ligands such as the Xaa-Cys-Yaa sequence in NiSODHC. In contrast, the Xaa-His-Yaa sequence in NiSODHH is not strong enough to cause spin pairing and a paramagnetic complex exists under physiological conditions (Xaa and Yaa denote amino acids with side chains which are not involved in the binding to the metal ion). This phenomenon clearly indicates that the thiolate group in the secondary position has a crucial role in the stabilization of square-planar geometry in the NiSOD. In previous studies the stabilization of the low spin state was attributed to the presence of two cysteine moieties in the coordination sphere, however, it is obvious from our spectroscopic data that the coordination of the secondary cysteine side chain alone is sufficient to induce spin pairing. ${ }^{10}$

An additional base consumption process results in the formation of the $\left[\mathrm{NiH}_{-1} \mathrm{~L}\right]^{2-}$ complex. Its formation is due to the deprotonation of tyrosine $\mathrm{OH}$ group. The corresponding deprotonation constant of this complex was calculated to be $p K_{a}=9.61$, which is close to the $\log K_{\mathrm{i}}$ of the ligand. Moreover, the calculated individual UV-Vis spectra do not show any significant differences, confirming that the coordination sphere of nickel(II) remains intact (Figure S11). 
The exclusive existence of this species was corroborated by ESI-TOF-MS spectroscopy (Figure S12).

As a conclusion, the two peptides exhibit different coordination equilibria with $\mathrm{Ni}$ (II) which is the consequence of the presence of cysteine in alternative positions. For NiSODHH, the paramagnetic complex is the major species under physiological conditions where the side chains of amino acid residues are involved in the metal binding. In contrast, NiSODHC is able to promote the ionization and coordination of the peptide nitrogen resulting in $(5,5)$ membered chelate system which is supported by macrochelation with the distant histidyl residue. In this case, the nickel(II) complex possesses square-planar coordination environment, consequently, the presence of cysteine in the secondary position of the peptide chain is crucial to establish this geometry in the reduced form of NiSOD, while the distant cysteine may affect the redox properties of the $\mathrm{Ni}(\mathrm{II}) / \mathrm{Ni}(\mathrm{III})$ couple.

\section{Oxidation and SOD activity of the nickel(II) complexes}

In order to model the enzyme mimetic behaviour of the nickel(II) complexes of the investigated ligands, $\mathrm{KO}_{2}$ and Oxone promoted oxidation were studied and the formation of nickel(III) transient species was monitored by EPR spectroscopy. Interestingly, both $\mathrm{KO}_{2}$ and Oxone are able to oxidize wtNiSOD and the experimental EPR parameters $\left(g_{x}=2.289, g_{y}=2.220, g_{z}=\right.$ 2.012; $\left.a_{x, y}{ }^{N}=17.5 \mathrm{G}, a_{z}{ }^{N}=25.2 \mathrm{G}\right)$ are in good agreement with those observed in the wild-type enzyme. Unfortunately, the nickel(II) complexes of NiSODHH and NiSODHC remain intact using $\mathrm{KO}_{2}$ or Oxone as an oxidizing agent and only the existence of free $\mathrm{O}_{2}{ }^{-}$anion was observed in the EPR spectra (Figure S13). The lack of the nickel(III) transient species can be explained by considering that the $(2 \mathrm{~N}, 2 \mathrm{~S})$ coordination environment of nickel is able to stabilize the $\mathrm{Ni}(\mathrm{III})$ - peptide complexes, but the oxidation process yields nickel(III) at too low concentration levels and it cannot be detected by the EPR method. However, the formation of an adduct between nickel(II) peptide complex and $\mathrm{O}_{2}^{-}$was observed under ESI-TOF-MS conditions. It 
is important to note that the $\left[\mathrm{NiH}_{-1} \mathrm{~L}\right]^{2-}$ complex of NiSODHH forms an adduct with the $\mathrm{O}_{2}$ dissolved in water (Figure S14) without any oxidizing agent $(\mathrm{m} / \mathrm{z}=562.18)$. This species is also detected when $\mathrm{KO}_{2}$ is added to the sample. The peak at $\mathrm{m} / \mathrm{z}=374.449$ confirms that the $\left[\mathrm{NiO}_{2} \mathrm{H}_{-1} \mathrm{~L}\right]^{3-}$ complex is also formed with $\mathrm{KO}_{2}$ This species is either a peroxo nickel(III) complex or a nickel(II) complex in which the thiolate group of the ligand is oxidized to sulfonate group (Figure 4).

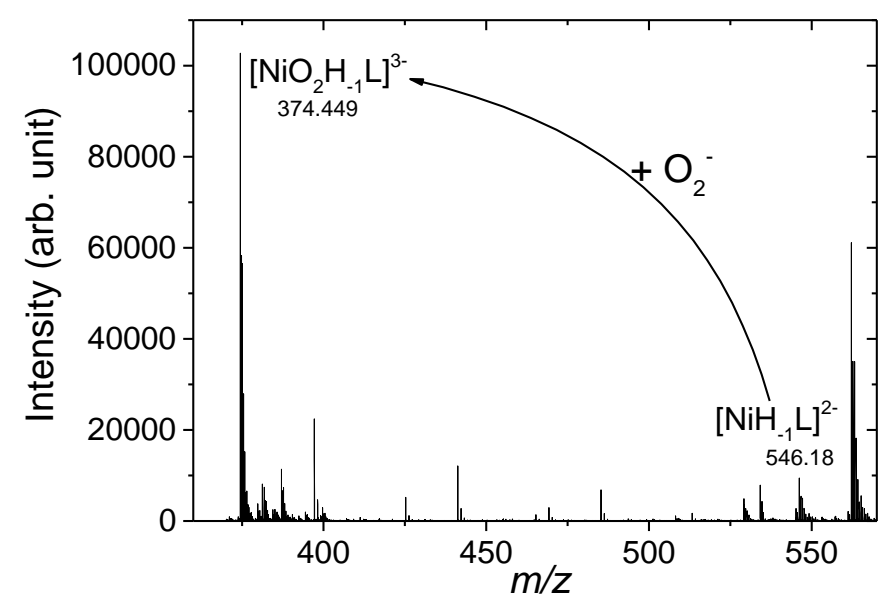

Figure 4. The ESI-TOF-MS spectrum of the $\left[\mathrm{NiH}_{-1} \mathrm{~L}\right]^{2-}$ complex in the $\mathrm{Ni}$ (II)/NiSODHH system after in situ oxidation with $\mathrm{KO}_{2}$. The assignments of the peaks are as follows: $\left[\mathrm{NiO}_{2} \mathrm{H}_{-1} \mathrm{~L}\right]^{3-}: m / z=374.449$ (calc: 374.451 ), $\left[\mathrm{NiH}_{-1} \mathrm{~L}\right]^{2-}: \mathrm{m} / z$ $=546.180$ (calc: 546.187$)$.

The SOD activity of the nickel(II) complexes was studied using the xanthine/xanthine oxidase/NBT system at $\mathrm{pH}$ 7.8. The structures of the major nickel(II) complexes under the conditions of SOD activity measurements are reported in the Supporting Information (Figure S15). The inhibition curves as a function of complex concentration are shown in Figure 5. It is important to note that the ligands did not exhibit any SOD activity and the species distributions were recalculated for each nickel(II) concentration used in the SOD activity studies. The species distributions clearly confirm that nickel(II) is bound to the ligands under these conditions and 
the complexes do not dissociate even at $\mu \mathrm{M}$ concentration level. Therefore, free nickel(II) does not affect the decomposition of the superoxide anion radical.
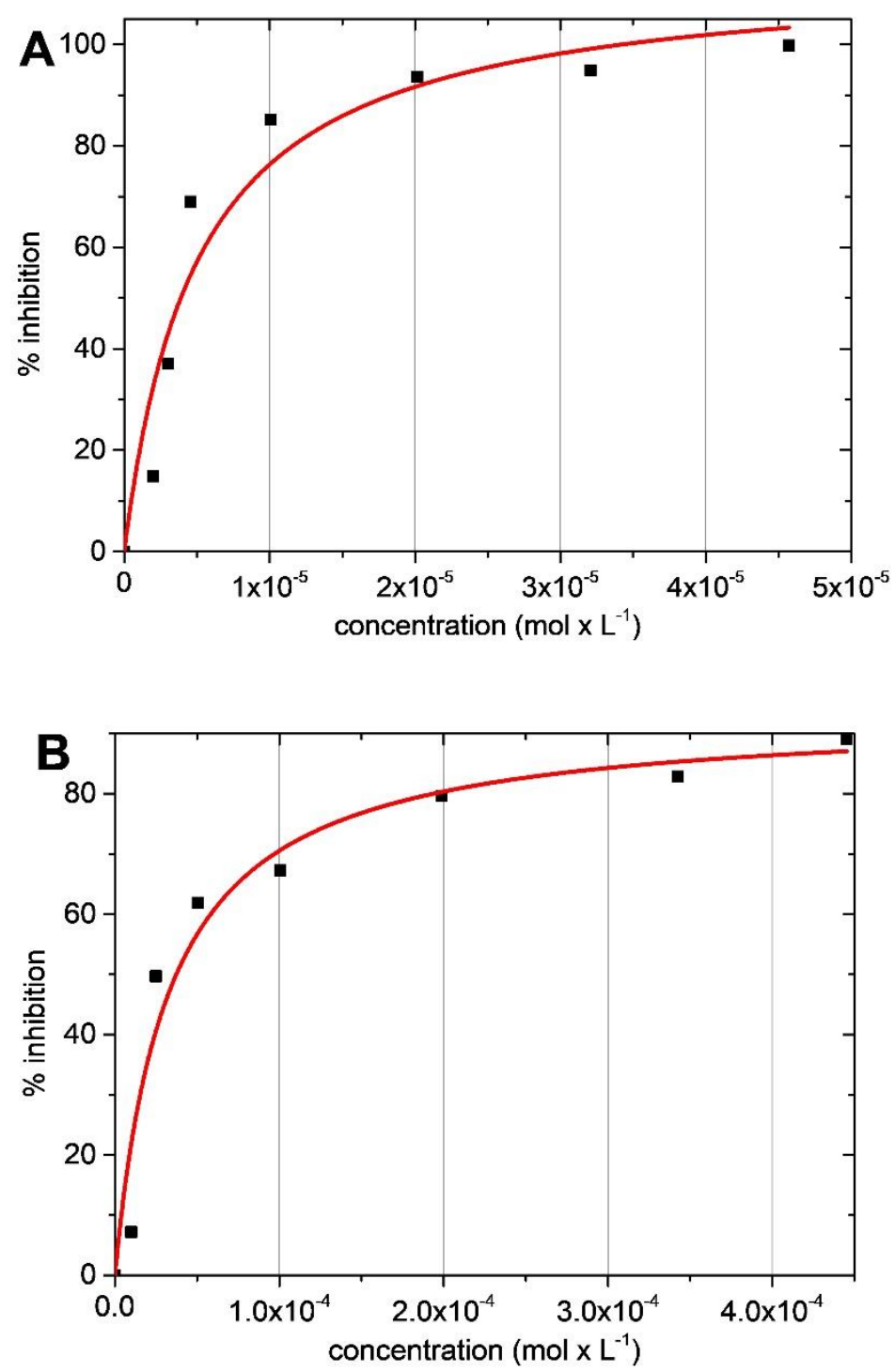


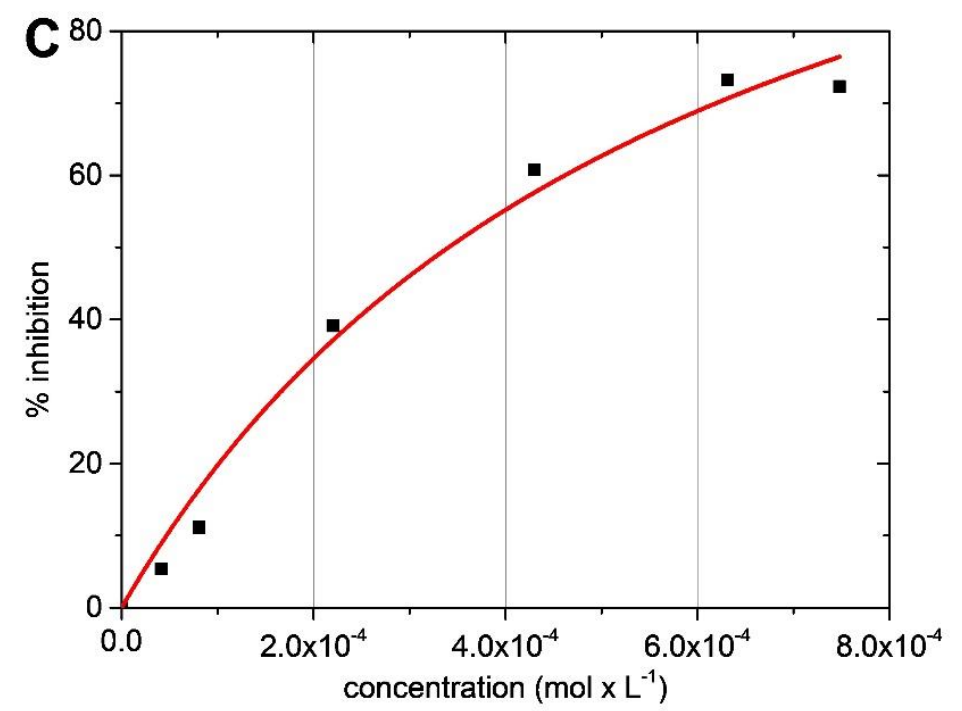

Figure 5. The inhibition percentage as a function of concentration of wtNiSOD (A), NiSODHC (B) and NiSODHH (C) at $\mathrm{pH} 7.8$

At pH 7.8, the $\mathrm{IC}_{50}$ was estimated to be $3.9 \mu \mathrm{M}, 37.4 \mu \mathrm{M}$ and $341 \mu \mathrm{M}$ for wtNiSOD, NiSODHC and NiSODHH, respectively. From the $\mathrm{IC}_{50}$ values it is possible to calculate the characteristic rate constant, $k_{M c C F}$, for the SOD activity (Eq. 2). ${ }^{25} 32$

$$
k_{\mathrm{McCF}}=k_{\mathrm{NBT}} \times[\mathrm{NBT}] / I C_{50}
$$

where $k_{\mathrm{NBT}}$ is $5.94 \times 10^{4} \mathrm{M}^{-1} \mathrm{~s}^{-1}$ for NBT (at $\mathrm{pH} 7.8$ ). In our tests the concentration of NBT was $45 \mu \mathrm{M}$.

Since $k_{M c C F}$ does not depend on the concentration of the detector molecule and its nature, it is frequently used to compare directly the activities of different SOD agents. The results of the SOD activity studies are summarized in Table 4.

Table 4. The $\mathrm{IC}_{50}$ values and the catalytic SOD activity of the investigated complexes.

\begin{tabular}{lll}
\hline Complex & $\mathrm{IC}_{50}(\mu \mathrm{M})$ & $k_{M c C F}\left(\mathrm{M}^{-1} \mathrm{~s}^{-1}\right)$ \\
\hline wtNiSOD & $3.9 \pm 0.2$ & $6.9 \times 10^{5}$ \\
NiSODHC & $37.4 \pm 0.3$ & $7.2 \times 10^{4}$ \\
NiSODHH & $341 \pm 5$ & $7.9 \times 10^{3}$ \\
\hline
\end{tabular}


The results clearly demonstrate that the complex formed with the wild-type fragment of NiSOD shows the best performance in the degradation of $\mathrm{O}_{2}{ }^{\bullet-}$. The activities of the complexes of NiSODHC and NiSODHH are smaller by one and two orders of magnitude, respectively. Earlier studies indicated that neither the length of the model peptides nor the substitution of His1 had an impact on the catalytic activity of the complexes. ${ }^{33}$ Only the acetylation of the terminal amino groups led to inactive NiSOD mimetic species. ${ }^{34}$

Sequential stopped-flow experiments were carried out, to explore the catalytic effect of these complexes in the decomposition of $\mathrm{O}_{2}^{-}$. The decay of this species was monitored at $250 \mathrm{~nm}$, and the characteristic kinetic traces are shown in Figure 6. As expected, the presence of the Ni complexes accelerates the disproportionation of the superoxide ion, however, the reaction is considerably slower with NiSODHC and NiSODHH than with wtNiSOD. The comparison of the half-times $\left(t_{1 / 2}\right)$ clearly demonstrates the differences in the catalytic activities. The half-time is $60 \mathrm{~s}$ in the absence of nickel complexes, while it is $3.9 \mathrm{~s}, 10.7 \mathrm{~s}$ and $48.2 \mathrm{~s}$ in the presence of wtNiSOD, NiSODHC and NiSODHH, respectively.

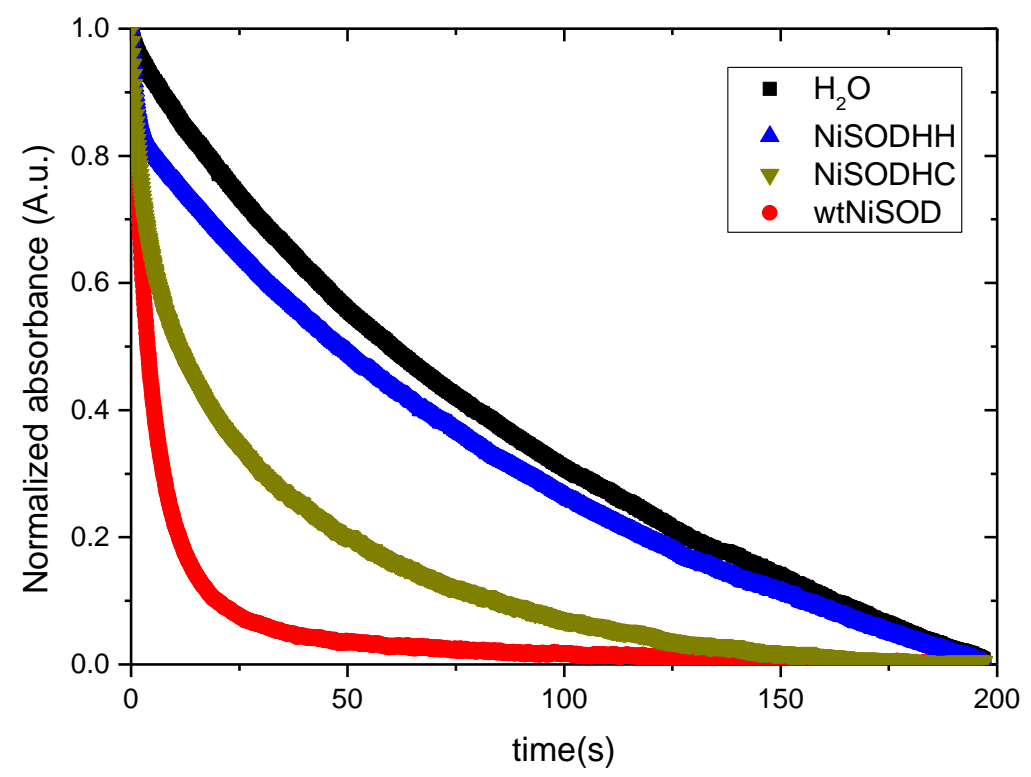

Figure 6. Kinetic curves for the decomposition of superoxide anion in the presence of nickel complexes (in 1:1 water/DMSO mixture). The curves were normalized for better comparison. $\lambda=250 \mathrm{~nm}, c_{\mathrm{O}^{-}}=460 \mu \mathrm{M}, c_{\mathrm{wtNiSOD}}=9.8 \mu \mathrm{M}, c_{\mathrm{NiSODHC}}=27.3 \mu \mathrm{M}, c_{\mathrm{NiSODHH}}=78 \mu \mathrm{M}$. 
These results strongly suggest that that the presence of both cysteinyl residues are essential in efficient degradation of superoxide. In the absence of these groups, the enzyme mimetic complexes are also capable to assist the decomposition of superoxide, however, their catalytic activity is considerably smaller.

\section{CONCLUSION}

In this paper, we report thermodynamic, structural characterization and SOD activity studies on nickel(II) complexes of nonapeptides mimicking the amino-terminal binding loop of the NiSOD enzyme. To better understand the role of the cysteine residues in NiSOD, the metallopeptides containing cysteine in alternating positions were studied and the results were compared with those observed with the wild-type fragment of NiSOD. Our study reveals that both peptide show efficient nickel(II) binding ability, however, the coordination modes of the corresponding complexes are different. The nickel(II) complex of the peptide containing histidine in the secondary position (NiSODHH) is paramagnetic and the $\left(\mathrm{NH}_{2}, \mathrm{~N}_{\mathrm{Im}}, \mathrm{N}_{\mathrm{Im}}, \mathrm{S}^{-}\right)$ coordinated complex is the dominant species at physiological $\mathrm{pH}$. The oxidation of the complex with $\mathrm{KO}_{2}$ leads to the formation of a $\mathrm{Ni}$ (III) complex, the existence of the corresponding $\mathrm{Ni}(\mathrm{III})$ $\mathrm{O}_{2}$ adduct was confirmed by ESI-TOF-MS method. The complex formation equilibria of NiSODHC exhibit different features. In this case, the N-terminal amino group acts as the primary metal binding site, however, the cysteine moiety in the secondary position induces the binding of the peptide nitrogen and thiolate groups in a cooperative manner. At physiological $\mathrm{pH}$, a diamagnetic square-pyramidal nickel(II) complex is the major species with the $\left(\mathrm{NH}_{2}, \mathrm{~N}^{-}\right.$ , $\mathrm{S}^{-}$) donor set in the equatorial plane which is supported by macrochelation via the distant 
histidyl residue. The exclusive existence of this species was corroborated by ESI-TOF-MS spectroscopy. The SOD activity and sequential stopped-flow studies demonstrate that the complex with the wild-type fragment of NiSOD shows the best performance in the degradation of $\mathrm{O}_{2}{ }^{\bullet-}$.

As a conclusion, cysteine in the secondary position of the peptide chain is crucial to establish the square-planar geometry in the reduced form of NiSOD, while the distant cysteine may affect the redox properties of the $\mathrm{Ni}(\mathrm{II}) / \mathrm{Ni}(\mathrm{III})$ couple. Thus, both cysteinyl residues are essential in the degradation of superoxide ion. In the absence of one of these groups, the SOD mimics are also capable to assist the decomposition of superoxide, but, the catalytic activity is considerably smaller.

\section{ACKNOWLEDGEMENT}

N.L. and I. F. are grateful for the financial support of the Hungarian National Research, Development and Innovation Office (NKFIH PD-128326 and K-124983). The research was also financed by the EU and co-financed by the European Regional Development Fund (under the projects GINOP-2.3.2-15-2016-00008). N. V. M. is grateful for the János Bolyai Research Scholarship of the Hungarian Academy of Sciences. The authors also thank Prof. Attila Gáspár for the ESI-TOF-MS measurements.

\section{ASSOCIATED CONTENT}

The Supporting Information is available free of charge on the ACS Publication website at DOI: titration curves, UV-vis and CD spectra as a function of $\mathrm{pH}$, ESI-TOF-MS spectra of the complexes, ${ }^{1} \mathrm{H}$ NMR spectrum, EPR spectra, structure of the complexes.

\section{AUTHOR INFORMATION}

\section{Corresponding Author}

*E-mail: 1ihi.norbert@ science.unideb.hu (N.L.) 


\section{ORCID}

Norbert Lihi: 0000-0003-2986-2395

Nóra V. May: 0000-0003-4770-4681

István Fábián: 0000-0002-4467-2912

\section{Notes}

The authors declare no competing financial interests.

\section{REFERENCES}

1. Sheng, Y.; Abreu, I. A.; Cabelli, D. E.; Maroney, M. J.; Miller, A.-F.; Teixeira, M.; Valentine, J. S. Superoxide Dismutases and Superoxide Reductases. Chem. Rev. 2014, 114 (7), 3854-3918 DOI: 10.1021/cr4005296.

2. Abreu, I. A.; Cabelli, D. E. Superoxide dismutases - a review of the metal-associated mechanistic variations. Biochim. Biophys. Acta 2010, 1804 (2), 263-274 DOI: https://doi.org/10.1016/j.bbapap.2009.11.005.

3. $\quad$ Fridovich, I. In Encyclopedia of Biological Chemistry; Lane, M. D., Ed.; Elsevier: New York, 2004; pp 135-138.

4. Miller, A.-F. Superoxide dismutases: active sites that save, but a protein that kills. Curr. Opin. Chem. Biol. 2004, 8 (2), 162-168 DOI: https://doi.org/10.1016/j.cbpa.2004.02.011.

5. Youn, H. D.; Kim, E. J.; Roe, J. H.; Hah, Y. C.; Kang, S. O. A novel nickel-containing superoxide dismutase from Streptomyces spp. Biochem. J. 1996, 318 (Pt 3), 889-896.

6. Shearer, J. Insight into the Structure and Mechanism of Nickel-Containing Superoxide Dismutase Derived from Peptide-Based Mimics. Acc. Chem. Res. 2014, 47 (8), 2332-2341 DOI: 10.1021/ar500060s.

7. Barondeau, D. P.; Kassmann, C. J.; Bruns, C. K.; Tainer, J. A.; Getzoff, E. D. Nickel Superoxide Dismutase Structure and Mechanism. Biochemistry 2004, 43 (25), 8038-8047 DOI: 10.1021/bi0496081.

8. Shearer, J.; Long, L. M. A Nickel Superoxide Dismutase Maquette That Reproduces the Spectroscopic and Functional Properties of the Metalloenzyme. Inorg. Chem. 2006, 45 (6), 2358-2360 DOI: 10.1021/ic0514344.

9. Johnson, O. E.; Ryan, K. C.; Maroney, M. J.; Brunold, T. C. Spectroscopic and computational investigation of three Cys-to-Ser mutants of nickel superoxide dismutase: insight into the roles played by the Cys2 and Cys6 active-site residues. Journal of biological inorganic chemistry : JBIC : a publication of the Society of Biological Inorganic Chemistry 2010, 15 (5), 777-793 DOI: 10.1007/s00775-010-0641-2.

10. Ryan, K. C.; Johnson, O. E.; Cabelli, D. E.; Brunold, T. C.; Maroney, M. J. Nickel superoxide dismutase: structural and functional roles of Cys2 and Cys6. J Biol Inorg Chem 2010, 15 (5), 795-807 DOI: 10.1007/s00775-010-0645-y.

11. Herbst, R. W.; Guce, A.; Bryngelson, P. A.; Higgins, K. A.; Ryan, K. C.; Cabelli, D. E.; Garman, S. C.; Maroney, M. J. Role of Conserved Tyrosine Residues in NiSOD Catalysis: A 
Case of Convergent Evolution. Biochemistry 2009, 48 (15), 3354-3369 DOI: 10.1021/bi802029t.

12. Krueger, H. J.; Holm, R. H. Stabilization of nickel(III) in a classical N2S2 coordination environment containing anionic sulfur. Inorg. Chem. 1987, 26 (22), 3645-3647 DOI: 10.1021/ic00269a002.

13. Kruger, H. J.; Peng, G.; Holm, R. H. Low-potential nickel(III,II) complexes: new systems based on tetradentate amidate-thiolate ligands and the influence of ligand structure on potentials in relation to the nickel site in [NiFe]-hydrogenases. Inorg. Chem. 1991, 30 (4), 734742 DOI: 10.1021/ic00004a025.

14. Fiedler, A. T.; Bryngelson, P. A.; Maroney, M. J.; Brunold, T. C. Spectroscopic and Computational Studies of Ni Superoxide Dismutase: Electronic Structure Contributions to Enzymatic Function. J. Am. Chem. Soc. 2005, 127 (15), 5449-5462 DOI: 10.1021/ja042521i.

15. Domergue, J.; Pécaut, J.; Proux, O.; Lebrun, C.; Gateau, C.; Le Goff, A.; Maldivi, P.; Duboc, C.; Delangle, P. Mononuclear Ni(II) Complexes with a S3O Coordination Sphere Based on a Tripodal Cysteine-Rich Ligand: $\mathrm{pH}$ Tuning of the Superoxide Dismutase Activity. Inorg. Chem. 2019, 58 (19), 12775-12785 DOI: 10.1021/acs.inorgchem.9b01686.

16. Lihi, N.; Csire, G.; Szakács, B.; May, N. V.; Várnagy, K.; Sóvágó, I.; Fábián, I. Stabilization of the Nickel Binding Loop in NiSOD and Related Model Complexes: Thermodynamic and Structural Features. Inorg. Chem. 2019, 58 (2), 1414-1424 DOI: 10.1021/acs.inorgchem.8b02952.

17. Csire, G.; Kolozsi, A.; Gajda, T.; Pappalardo, G.; Várnagy, K.; Sóvágó, I.; Fábián, I.; Lihi, N. The ability of the NiSOD binding loop to chelate zinc(ii): the role of the terminal amino group in the enzymatic functions. Dalton Trans. 2019, 48 (18), 6217-6227 DOI: 10.1039/C9DT01015G.

18. Dupont, C. L.; Neupane, K.; Shearer, J.; Palenik, B. Diversity, function and evolution of genes coding for putative Ni-containing superoxide dismutases. Environ. Microbiol. 2008, 10 (7), 1831-1843 DOI: 10.1111/j.1462-2920.2008.01604.x.

19. Gran, G. Determination of the equivalence point in potentiometric titrations. Part II. Analyst 1952, 77 (920), 661-671 DOI: 10.1039/AN9527700661.

20. Irving, H. M.; Miles, M. G.; Pettit, L. D. A study of some problems in determining the stoicheiometric proton dissociation constants of complexes by potentiometric titrations using a glass electrode. Anal. Chim. Acta 1967, 38, 475-488 DOI: https://doi.org/10.1016/S00032670(01)80616-4.

21. Gans, P.; Sabatini, A.; Vacca, A. SUPERQUAD: an improved general program for computation of formation constants from potentiometric data. Journal of the Chemical Society, Dalton Transactions 1985, (6), 1195-1200 DOI: 10.1039/DT9850001195.

22. Nagypál, L. Z. a. I. "Computational Methods for the Determination of Formation Constants," in Computational Methods for the Determination of Stability Constants, D. Leggett, Ed., pp. 291-299, Plenum Press, New York, NY, USA. 1985.

23. MATLAB and Statistics Toolbox Release 2012b, T. M., Inc., Natick, Massachusetts, United States.

24. Rockenbauer, A.; Korecz, L. Automatic computer simulations of ESR spectra. Appl. Magn. Reson. 1996, 10 (1), 29-43 DOI: 10.1007/BF03163097.

25. Durot, S.; Policar, C.; Cisnetti, F.; Lambert, F.; Renault, J.-P.; Pelosi, G.; Blain, G.; Korri-Youssoufi, H.; Mahy, J.-P. Series of Mn Complexes Based on N-Centered Ligands and Superoxide - Reactivity in an Anhydrous Medium and SOD-Like Activity in an Aqueous Medium Correlated to MnII/MnIII Redox Potentials. Eur. J. Inorg. Chem. 2005, 2005 (17), 3513-3523 DOI: 10.1002/ejic.200400835. 
26. Goldstein, S.; Michel, C.; Bors, W.; Saran, M.; Czapski, G. A critical reevaluation of some assay methods for superoxide dismutase activity. Free Radic. Biol. Med. 1988, 4 (5), $295-$ 303 DOI: https://doi.org/10.1016/0891-5849(88)90050-0.

27. Sóvágó, I.; Várnagy, K.; Lihi, N.; Grenács, Á. Coordinating properties of peptides containing histidyl residues. Coord. Chem. Rev. 2016, 327-328, 43-54 DOI: 10.1016/j.ccr.2016.04.015.

28. Sovago, I.; Osz, K. Metal ion selectivity of oligopeptides. Dalton Trans. 2006, (32), 3841-3854 DOI: 10.1039/B607515K.

29. Farkas, E.; Sovago, I.; Kiss, T.; Gergely, A. Studies on transition-metal-peptide complexes. Part 9. Copper(II) complexes of tripeptides containing histidine. Journal of the Chemical Society, Dalton Transactions 1984, (4), 611-614 DOI: 10.1039/DT9840000611.

30. Sovago, I.; Farkas, E.; Gergely, A. Studies on transition-metal-peptide complexes. Part 7. Copper(II) complexes of dipeptides containing L-histidine. Journal of the Chemical Society, Dalton Transactions 1982, (11), 2159-2163 DOI: 10.1039/DT9820002159.

31. Raics, M.; Lihi, N.; Laskai, A.; Kállay, C.; Várnagy, K.; Sóvágó, I. Nickel(ii), zinc(ii) and cadmium(ii) complexes of hexapeptides containing separate histidyl and cysteinyl binding sites. New J. Chem. 2016, 40 (6), 5420-5427 DOI: 10.1039/C6NJ00081A.

32. Liao, Z.-R.; Zheng, X.-F.; Luo, B.-S.; Shen, L.-R.; Li, D.-F.; Liu, H.-L.; Zhao, W. Synthesis, characterization and SOD-like activities of manganese-containing complexes with $\mathrm{N}, \mathrm{N}, \mathrm{N}^{\prime}, \mathrm{N}^{\prime}$-tetrakis(2'-benzimidazolyl methyl)-1,2-ethanediamine (EDTB). Polyhedron 2001, 20 (22), 2813-2821 DOI: https://doi.org/10.1016/S0277-5387(01)00891-9.

33. Shearer, J.; Neupane, K. P.; Callan, P. E. Metallopeptide Based Mimics with Substituted Histidines Approximate a Key Hydrogen Bonding Network in the Metalloenzyme Nickel Superoxide Dismutase. Inorg. Chem. 2009, 48 (22), 10560-10571 DOI: 10.1021/ic9010407.

34. Tietze, D.; Sartorius, J.; Koley Seth, B.; Herr, K.; Heimer, P.; Imhof, D.; Mollenhauer, D.; Buntkowsky, G. New insights into the mechanism of nickel superoxide degradation from studies of model peptides. Sci. Rep. 2017, 7 (1), 17194 DOI: 10.1038/s41598-017-17446-3.

\section{TOC Graphic}

The metallopeptides containing cysteine in alternating positions were studied to better understand the role of the cysteine residues in NiSOD. The results indicate that, both cysteinyl residues are essential in the degradation of superoxide ion. In the absence of one of these groups, the SOD mimics are also capable to assist the decomposition of superoxide, but, the catalytic activity is considerably smaller.

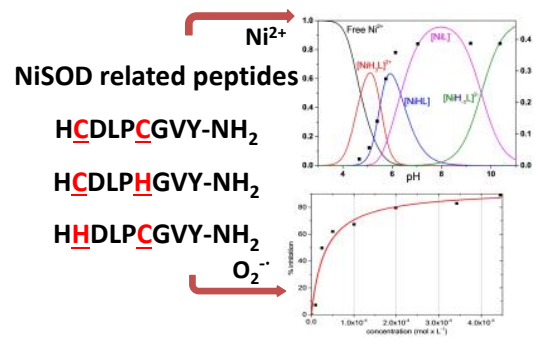

